This is an Accepted Manuscript of an article published by Taylor \& Francis in Sociological Spectrum on November 23, 2015 available online: https://www.tandfonline.com/doi/abs/10.1080/02732173.2015.1086287

\title{
THE EXPERIENTIAL GAP IN DISASTER RESEARCH: FEMINIST EPISTEMOLOGY AND THE CONTRIBUTION OF LOCAL AFFECTED RESEARCHERS
}

\author{
Kristen Barber, Ph.D. \\ Assistant Professor of Sociology \\ Southern Illinois University, Carbondale \\ AND \\ Timothy J. Haney, Ph.D. \\ Associate Professor of Sociology \\ Director, Centre for Community Disaster Research \\ Mount Royal University
}

In this article, we make the case for a situated knowledge of disasters. By applying a feminist standpoint framework, we argue that an ethic of "objectivity" and a privileging of the unattached researcher creates an experiential gap in the disaster literature whereby researchers who themselves experience disaster are undervalued and underrepresented. We analyze reflexive accounts by disaster researchers to show what epistemological barriers emerge from conventional processes of inquiry and the systematic disadvantaging of local, affected researchers. We also study patterns in articles by "outsider" and "insider" researchers, focusing on differences and similarities in research questions, reflexivity, relationships with and access to participants, and larger theoretical goals. This comparison reveals that the unique position of affected researchers can help to bridge formal knowledge and practical life knowledge, creating new and worthwhile paths to understanding the social effects of disaster.

Acknowledgements: We would like to thank Joey Sprague and Kirsten Dellinger for their helpful comments on earlier drafts of this paper. We also thank Shiloh Deitz and Morah Mackinnon for their expert research assistance.

Correspondence may be addressed to Kristen Barber, Department of Sociology, 3436 Faner Hall, Southern Illinois University-Carbondale, Carbondale, IL 62901; phone: (618) 453-7633; e-mail: barber@siu.edu 


\section{THE EXPERIENTIAL GAP IN DISASTER RESEARCH: FEMINIST}

\section{EPISTEMOLOGY AND THE VALUE OF LOCAL AFFECTED RESEARCHERS}

Disasters evoke strong emotions due to their often unpredictable nature and fast onset, as well as the potential for catastrophic losses of wealth, structural support, and human life. Yet those who study disaster are typically from outside an affected area, do not experience an event firsthand, and are removed from the emotional trauma of disaster and recovery. This is not surprising since it might be difficult for local affected researchers to design and implement research procedures when they are struggling with the material and psychological affects of disaster (Haney and Elliott 2013; Henderson et al. 2008). But also, a historical tradition within the social (and natural) sciences privileges outsider researchers as less emotional and attached, and thus supposedly more objective and better situated for getting at "truth" than insiders (Bordo 1987; Fee 1981; Longino 1990).

While sociology has a history of upholding "objectivity" as the gold standard of research, feminist standpoint epistemologists argue that it is a mistake to assume the identity of an observer is ever irrelevant in research (Harding 1986). This perspective suggests the concept of objectivity serves those with power, situating particular researchers as appropriate authorities in the production of value-free knowledge while also veiling the impact their biographies have on which questions they ask, who they study, and what they find. Smith (2004:88) argues that we cannot separate "the knower from what $[\mathrm{s} / \mathrm{h}$ he knows", and that there is no such thing as a "view from nowhere" (Nagel 1986). If we take seriously the perspective that researchers' social locations, or standpoints, impact their work, then there is room to value the work of insider researchers who may be motivated by their own lived experiences, such as that of disaster. 
In this paper, we apply a feminist standpoint framework to ask: What are the epistemological possibilities when we support disaster research by those who are themselves affected? Within this broader question, we situate a narrower question involving the need to take seriously the role of researchers' emotions in studies of disaster: How might experiences of disaster help local researchers to ask different questions, gain rapport, and empathize with and access the emotional subjectivities of participants? We are interested in how the personal and emotional familiarity with a disaster can help scholars to bridge the experiential gap that exists in current disaster literature, where our knowledge about the social effects of disaster is shaped heavily by outsider researchers.

In the sections that follow, we make the case for a situated knowledge of disasters, crises, and catastrophes. We explain what feminist approaches to understanding standpoint, research, and epistemology have to offer, and then discuss how disaster work often fails to account for researcher experience. Drawing from the reflexive accounts of disaster researchers, we unpack the epistemological barriers the outsider status creates during face-to-face investigations. Using Hurricane Katrina as an example, we pull from a brief but systematic analysis of published qualitative research on Hurricane Katrina to demonstrate how local scholars create the very sort of knowledge we are advocating — a knowledge that is reflexive and relies upon personal experiences with disaster to guide inquiry, rather than rejecting personal experience and emotion as bias. This work, we argue, while still marginalized within a largely positivist discipline, has the potential to create a more comprehensive understanding of the social effects and experiences of disaster. SITUATED KNOWLEDGE AND THE EPISTEMIC RELEVANCE OF RESEARCHERS' EXPERIENCES 


\section{Connecting Knowing and Knowledge}

The privileging of objectivity persists in scientific discussions of knowledge despite the efforts of feminist scholars who, in the late 1980s and 1990s, held a critical lens to conventional scientific epistemology, criticizing it as a way to further silence already marginalized groups such as women and racial minorities (Collins 1986; 1990; 1997; Haraway 1988; Harding 1986; Longino 1989). Framed as overly emotional and thus irrational and incapable of objectivity, such groups have been historically and institutionally delegitimized as authorities in the sciences (Jagger 1989). And the idea that some researchers are able to divorce their deep-seated biases and interests from their work continues to characterize academic definitions of "real" or "good" science. Highlighting what Haraway (1988:581) refers to as the "god trick", the notion of an unbiased and disembodied researcher gives authority to represent the world to scholars who appear unemotional and unattached from what they study. They speak without locating themselves in relation to their research, appearing as voices of rationality and truth. Feminist standpoint epistemology, however, encourages scholars to recognize that all knowledge is situated, since it emerges from scholars who hold particular social positions, degrees of power, and particular interests; and who are therefore limited in their ability to explore and explain the world (Harding 2003). From this perspective, emotional investment in and personal experience with a research community are not hindrances to epistemological pursuits, but a valuable perspective or standpoint that contributes to our knowledge about a larger topic.

Standpoint epistemologists argue that much research is informed by masculinist perspectives steeped in voyeurism and objectification of the "subject." This is often true in disaster research, where even the "how to" books for disaster fieldwork frame those affected by disaster as passive, vulnerable victims (Fleischman, Collogan, and Tuma 2006; Jones et al. 
2006), instead of as agents making the best decisions available to them (e.g., Pardee 2014, who lived in New Orleans at the time of Hurricane Katrina). The outsider gaze has also long colonized the voices of marginalized groups, and feminist scholars urge investigators to be "mindful of hierarchies of power and authority in the research process" (Hesse-Biber 2012:4). Hesse-Biber and Leckenby (2004) argue that feminist epistemology is not the result of a particular method (interviews over statistical analysis, for example), but rather emerges from a reflexive approach that considers how power and perspective shape all stages of research. Feminist epistemology particularly values the contributions of researchers who have unique perspectives on processes of injustice, such as how structural inequalities differently shape people's vulnerability to disaster (David and Enarson 2012; Enarson 2012).

Sprague (2005) notes that researchers who are not part of the communities they study risk creating knowledge about an event or a community by evoking an "us vs. them" discourse that objectifies participants. This is due partly to differently available cultural scripts, she says. Outsider researchers' limited local knowledge shapes what they see and how they interpret events, and the frames by which they make sense of a phenomenon may marginalize local voices. While "insiders" might overlook the significance of mundane processes within their communities, "outsiders" have the advantage of looking at an event with fresh eyes (Sprague 2005). Yet, all of this rests on the idea that researchers are either outsiders or insiders, and overlooks the unique position—and ultimately the epistemological possibilities and insights—of researchers who are both located within an affected community and come to the table with formal outsider knowledge. Local affected researchers are not "outsiders within" as Collins (1986) describes them: those disadvantaged by their social location(s) but present in privileged settings and hence uniquely situated to recognize the operations of both privilege and 
disadvantage. However, with substantial a priori knowledge of local history and geography, firsthand experience of the event, and long-term and ongoing commitment to the affected region, local researchers have unique perspectives that blend personal experience with scholarly insight. Contrary to Collins' outsiders within category, we suggest that local affected researchers might be considered "insiders without." That is, they are a group who experiences an event firsthand and are familiar with local social dynamics, yet also face scholarly disadvantages including less grant funding, less institutional support, and less ability to strategically detach from the work.

In advocating for the inclusion of marginalized groups into social science research, Smith (1987) identifies the difference between practical life knowledge and formal knowledge. She notes that people come to know as they go about their lives, becoming expert practitioners of their everyday worlds. They develop practical ways of knowing as subjects; yet, this knowing is often separate from more abstract formal knowledge embodied in texts, experts, organizations, and ideologies. Formal knowledge tends to be far removed from and could even erase the grounded experiences of those at the margins. As a result, researchers might represent participants including victims of disaster in ways that do not resonate with them, and at times even harm them (Sprague 2005); for example, if researchers overlook those issues and concerns most crucial for generating needed policies within communities. Although Smith argues that researchers must take seriously women's ways of knowing to affect social change, dismantling the divide between knowing and knowledge may come more generally from scholars who are local to a community. Those researchers who experience disaster are knowers who have an understanding of social life in an affected region precisely because they too live there, but they are also in the business of producing formal knowledge. From the perspective of Smith, then, we can understand the emotionally invested, local affected researcher as uniquely situated to connect 
knowing and knowledge, and to overcome some issues of participant objectification and problematic framing of disasters.

Local Researchers' Emotions as Data

Local researchers are at risk of being seen by other scholars as too close to a phenomenon and, by extension, too emotional or biased to view an event objectively. The idea that emotions impede epistemic ventures is debated in philosophic discussions on the relevance of emotions in creating knowledge and on what to do with that knowledge (e.g. social activism) (Brun, Doguoglu and Kuenzle 2008; Gorton 2007). Emotions, though, need not stand in stark contrast to valid knowledge. Instead, feminist epistemologists suggest we should understand that generating knowledge is fundamentally tied up with experience and feeling, and that emotionsincluding those of the researcher themselves - are and should be central to understanding and interpreting social phenomena. If we "discard our experiences," Smith (2004:88) says of researchers, then we risk reinforcing "conceptual imperialism." If we support the work of local researchers who themselves have dealt with trauma and are attempting to understand the events that unfolded, however, we can perhaps generate a disaster literature that reveals different social processes of disaster.

Valuing, encouraging, and supporting the work of local affected researchers has possibilities for creating new paths to knowledge. This is because their experiences and emotions allow them to not only better understand how their epistemic projects are situated or created from particular standpoints and fields of power (Collins 1986; 1990), but at times also to gain the trust of affected populations and ultimately to bridge the experiential gaps that we will show are at risk of forming in disaster research by outsiders. Disasters, which by definition evoke strong feelings of anger and sadness, can affect how people respond to requests to participate in 
research, as well as impressions of how well an outsider might understand or empathize with a particular disaster experience. Our task is to apply empirically the understanding that it is disingenuous to study phenomena such as disasters without acknowledging the feelings that go along with them. And in doing so, we call for the larger scholarly community to value the experiences of local affected researchers as important to creating a more inclusive and diverse understanding of disaster.

Valuing researchers' emotions as rational reactions to larger social phenomena also helps to undo masculinist research practices that both mask feelings and marginalize researchers who appear too close to an issue. As Sprague (2005:135) contends, emotions may be key to uncovering particular patterns of data:

Emotions are the personal links to the social, and researcher introspection is a strategy for social research. When one is studying a community in which one has played a role, interactions with other members are not just occasions for collecting information. Rather, these interactions are instances of that community's practices, shaped by its values. Thus the researcher's feelings about those interactions are primary data about the community. In addition to easing entrée and evoking empathy in research interactions, researchers' own emotional and highly personal experiences with disaster shape data by informing the questions they ask, and act as clues to larger processes within a community. "[E]motions are an expression of the nature of a relationship — to a community and/or to an individual member of that community — and thus valuable data about that relationship. Investigators cannot help but respond emotionally to what - and whom - they are studying, and these emotions are bound to influence emphases and interpretations" (Sprague 2005:136). Instead of seeing this as a problem, feminist scholars suggest that researchers' emotive experiences may tell us things about a place, 
including collective experiences, local identities, and community concerns. This approach supports reflexive scientific endeavor that takes seriously the role of the researcher in shaping the research and appreciates the connection between experience, emotions, questions, relationships, and data.

Key theoretical debates such as the value of positionality and experience in the creation of knowledge will help to craft more inclusive disaster sociology and to address key sociological concerns such as intersecting inequalities. As Tierney (2007:504) points out, disaster research has sat at the "margins" of sociology: "if longstanding practices prevail, this already marginalized field risks becoming irrelevant within the broader discipline of sociology." She notes that disaster sociologists must situate their work within central sociological debates, rather than appeasing only the applied disaster research community, so as to "concentrate on problems that are meaningful to the discipline. They must integrate the study of disasters with core sociological concerns, such as inequality" (520). Quartantelli (2005:330) similarly points out that "We will do better disaster studies by being better sociologists." We show how emerging research from insider scholars lead to new veins of disaster research, focusing on topics and issues that emerge as part of local researchers' experiences with disaster and offering unique contributions to current understandings of disaster.

\section{METHODS}

It is difficult to demonstrate empirically that the insider voice is largely missing from disaster research. This is because it is challenging to operationalize "insider" and "outsider" statuses, and to identify the absence of situated or experiential knowledge. It is much easier to demonstrate the presence of something rather than its absence, and yet more difficult to describe what that missing element looks like should it exist. Still, we investigate the lacuna of "insider" 
voices and experiences in three ways. First, we pull from reflexive accounts of outsider disaster researchers who discuss epistemological challenges while in the field. These observations illustrate the problems sometimes posed by "in and out" disaster research and come from methods sections and appendices, as well as the main analyses of monographs and journal articles. Yet locating these reflections was not easy; we discovered that the vast majority of disaster research is done without reflexive analyses, engaging Haraway’s (1988) "god trick."

Second, we discuss some of the ways knowledge about one particular disaster (Hurricane Katrina) flowed largely from outside of the affected region. Looking at the National Science Foundation's Award Search Interface, we show that NSF funding for Hurricane Katrina research was awarded mainly to outsider researchers. This evidence helps us to establish and illuminate some of the mechanisms by which outsiders are privileged at the cost of disempowering local affected researchers to conduct work in the aftermath of disaster.

Third, we demonstrate, through an EBSCOhost search for sociological Hurricane Katrina articles, that local affected researchers pen only a minority of this work, and that these articles are more reflexive than those written by outsiders. EBSOhost is a large database that catalogues articles from numerous related journals, including Disasters. We conducted a systematic analysis of a random sample of 30 qualitative research articles on Hurricane Katrina. We focus on Hurricane Katrina as an example of a recent disaster that has spurred much research into the multifaceted affects of trauma and crisis, and that has also seemingly invigorated academic and popular interest in disaster. For example, the 1972 "Buffalo Creek Flood," which was the subject of Kai Erikson's (1976) influential book, Everything in It's Path, yielded only 92 academic sources from an EPSCOhost search (3.29.2014). A simultaneous search for "Hurricane Katrina," which occurred in 2005 , resulted in 101,630 sources. 
In the next section, we examine our findings from these three analyses in hopes that this work will start a dialogue amongst disaster researchers on taken-for-granted barriers outsiders have faced in disaster research, the uneven distribution of research funds that support disaster research, hidden traditions of investigating disasters in ways that privilege outsiders as objective, and how personal, emotional experiences may provide local researchers' unique insights into the social effects of disaster.

\section{OUTSIDER STATUS AND BARRIERS IN DISASTER RESEARCH}

\section{Accessing and Understanding the Experiences of Locals}

Positivists generally argue that any qualified researcher should be able to arrive at the same conclusions as anyone else-given appropriate methods — and so experience should not impact how we understand phenomena. Parsons ([1937] 1968:348) clarifies this position, arguing, "the distinguishing characteristic of the empirical element is its objectivity, its independence of the subjective inclinations, sentiments or desires of the observer. A fact is a fact whether we like it or not." If this was the case, firsthand experience should not matter when researching or writing about disasters. Yet, disasters are very unique events in that

People experience a vast spectrum of intense emotions - anxiety, fear, terror, loss, grief, gratitude, anger, frustration, relief and resignation - in all their shadings and intensities. These emotions color their experiences of preparation (if any), the event itself, and the aftermath of a disaster for indefinite periods of time (Oliver-Smith and Hoffman 1999:163).

Even 40 years ago, Erikson (1976:11) knew that experiencing a disaster was so cataclysmic, emotional, and life changing, that unbridgeable gaps of understanding form between those who experience an event and those who do not. While studying the Buffalo Creek Flood, he writes 
about the significance of being an outsider, noting that locals were "So wounded in spirit that they almost constituted a different culture, as though the language we shared in common was simply not sufficient to overcome the enormous gap in experience that separated us." Although gleaned from months of in-depth interviewing, Erikson's description of the Buffalo Creek community may not have captured the intensity and immediacy of the disaster experience as understood by local residents. He works to portray reality as locals described it to him, but he also admits his outsider status created a cleft between him and his participants that affected his data.

As Erikson suggests, locals may be unwilling or unable to fully describe to an outsider the emotional and material turmoil of their community. Admittedly, this problem is not unique to non-affected researchers. Following Hurricane Katrina, Marks (2008:14), a New Orleanian, wrote, "It was clear to me that words, no matter how descriptive or genuinely expressed, were not sufficient to 'tell the story.' They were like a small two-dimensional photograph or post-card of the Grand Canyon which can never convey the majesty and full ambiance of that place." If those affected struggle themselves to describe the event and their associated feelings, it would be even more difficult for a removed researcher to do justice to the complexity of those feelings. For example, it may be difficult for someone who lived through an event to communicate to an outsider the horror of disaster, or to convince them of the injustice and mishandling that accompanies government response. Outsider researchers who discuss the significance of their locations, such as Erikson, suggest the gap between practical life knowledge and the formal processes of epistemic ventures (Smith 1987) limit researchers' insights. Such reflexive efforts open the door for a situated knowledge of disasters. 
Feminists have argued that the "distinctly episodic structures" of some people's lives make it difficult for others to understand, especially when they come into a situation with a different way of experiencing and framing the world. Both Erikson and Smith assert that while outsiders are used to thinking in linear terms along a timeline that is logically ordered and moves predictably, insiders experience an irregular flow of time that might be perplexing to someone not similarly experiencing a rearranging of their life. The sequence in which people live out their everyday lives and the timing of previously taken-for-granted practices, including going to and from work, dropping children off at school, and participating in usual leisure activities, are turned upside down during and after disaster. The ways people experienced and reorganized their lives after the Buffalo Creek flood were so complex that Erikson (1976:212) doubted his ability to capture and portray those experiences: "There was history before, an orderly and calculable sequence of time, but there has been nothing since other than a blurring of logic and a collapse of meaning." Disaster researchers have begun to discuss this phenomenon as the loss of one's ontological security, or the "sense of safety, routine, and trust in a stable environment" (Hawkins and Maurer 2011:148). Familiar landmarks and normal routines are disturbed by disaster, fragmenting and distorting the lives of affected persons and making it difficult for locals to describe to someone not similarly experiencing them and for researchers to understand and capture this process. And although affected persons may have difficulties communicating such disruptions, they will likely better understand and develop questions around these issues than outsiders.

Very little disaster research—even ethnographic work—contains reflexive discussions of outsider limitations to understanding local experiences. In one rare reflexive account, Fothergill (2004:225), who studied women affected by the 1997 Red River Flood, discusses the strong 
relationships she formed with participants. As an outsider who did not experience the flood firsthand, she argues that, "Over time, however, I took on a participant-as-observer role, as I developed in-depth relationships, made formal and informal observations, and established relationships with informants who trusted me and interacted with me as friends." She suggests that she did not have to experience the disaster to be a participant; instead, she became a participant by forming relationships with those who experienced the event. She acknowledges, though, that "One barrier to more central membership was that I did not live in or near my setting, thereby limiting my contact and relegating me to being 'with' but not 'part of' the group" (Fothergill 2004:225). Being "with" instead of "part of" the group has implications for the researcher's access to participants' interactions and interpretive perspectives, and ultimately to the analytic conclusions about the effects of disaster on their community.

In a more recent example, Adams (2013) provides a political and economic critique of the slow pace of recovery in post-Katrina New Orleans. Although her work grew out of relationships with local people, she made the final choices about how to analyze the data, which excerpts to choose, and how to construct the central argument without a local's knowledge of New Orleans' geography and history. She stresses that, "although the analysis is generated from the empirical ground of events and phenomena witnessed in the recovering city, not all the members of my team or even all the people who live in New Orleans will agree with my diagnosis in all or, for some, in part" (Adams 2013:192). As Smith (1990:24-25) points out, the researcher may not be well positioned to tell stories for those who experienced an event firsthand. After seeing a group of Aboriginal Canadians from the window of a passing train, she realized I could tell this incident... as it was, but that my description was built on my position and my interpretations. I have called them "Indians" and a family; I have said 
they were watching the train. Everything may have been quite different for them... If we begin from the world as we actually experience it, it is at least possible to see that we are indeed located and that what we know of the other is conditional upon that location.

Non-local people can and certainly do pen important work about disasters, but that work may miss important nuances, misrepresent the experiences and desires of local peoples, and be sharpened by including local researchers as collaborators.

\section{Conflict with Affected Communities}

Disasters prompt experts from around the world to mobilize their research dollars and to travel to affected areas in hope of understanding the causes and consequences of an event, and of making policy recommendations regarding disaster preparedness and recovery. Why then might locals affected by disaster resist outsider researchers? Outsider experts and community members may differently understand the region's problems and needs. This conflict can create resistant locals who do not want outsider frameworks of such an emotional, traumatic, and even political event placed upon them (Button 2010). After all, scientific method traditionally privileges the voice of the supposed objective researcher over the voice of (sometimes long marginalized) local people (Collins 1986; 1990; Haraway 1988; Harding 1986; Longino 1989; Nagel 1986). Below, we discuss four ways outsider researchers risk coming into conflict with local communities who struggle to be heard and who may resent submitting to the formal knowledge of these scholars.

First, locals have found that outsider researchers silence their voices. Soon after danger passes, locals create discourse and practical life knowledge (Smith 1987) about an event. As they grapple with their experiences of and attempts to recover from disaster, those affected also make sense of what has happened and why. This meaning-making process takes place alongside the production of formal knowledge by outsider researchers. According to Button (2010:168), 
Disaster victims and their communities struggle not only to regain control over their lives but also to refute the objective frames offered by experts and mirrored by the media... Attempts to silence lay voices in instances like these undermine alternative discursive frames of explanation and preclude analyses of catastrophes in a way that would fully allow unpacking the politically powerful world of social relations in which catastrophes and the calamity that follow are grounded.

Button reveals that alternative frames for understanding disaster may be overlooked by maintaining a distinction between "expert" and "community member," or an objectifying us vs. them relationship (Collins 1986; 1990; Sprague 2005). This suggests that disaster research, when conducted by those from the outside, risks creating an additional layer of conflict for people who struggle to shape or reshape discourses being created about them. While scholars are better prepared to connect an event to existing theories and bodies of empirical knowledge, they may also unintentionally silence local voices and maintain a dichotomy between knowing and knowledge (Smith 1987).

Second, problems arise not only with the silencing of locals but also with the privileging of scholarly voices and the dubbing of researchers — rather than locals — as "experts." This is particularly the case in epic approaches that inform much quantitative sociological work. Following the 1984 Bhopal, India toxic gas release, Fortun (2001:218) notes, "key legal and judicial processes took place in spaces (boardrooms, courts, etc.) that excluded locals." One of the reasons for this exclusion involves conflict between a rational-scientific view of the disaster and a more emotional, contextual view (Brun et al. 2008; Gorton 2007; Jaggar 1989). OliverSmith and Hoffman (1999:163) similarly argue that "There is a distinct tendency, even in the choice of issues studied, to equate emotionality with irrationality and to denigrate as irrational 
those forms of collective behavior in which emotions prevail in orienting action and setting goals." Traditional scientific methods that depend on hypothesis testing, operationalization, and objective analysis of data are often at odds with the outlook of locals, whose emotional understandings may be viewed as unscientific (Smith 1987; 2004; Sprague 2005). This is a problem as social scientists have accepted a significant degree of influence over policy and litigation and have more potential than ever to influence the material realities of affected persons (Beck 2009). This influence reflects both the power and responsibilities researchers have to represent the voices of those they study and the potential for colonizing marginalized groups who are not considered experts (Hesse-Biber 2012).

Even when affected researchers attempt to integrate place-based nuance into their work, it passes through the filter of non-local referees. As much as local context (history, culture, geography, parlance) matters in the creation of knowledge on disasters (Campanella 2007), the need to understand and incorporate this context may escape reviewers and editors who decide the quality of research. As Haney and Barber (2013) demonstrate, the context-specific knowledge of local, familiar researchers may be filtered out by reviewers and editors who seek broad, generalizable findings and conclusions that can be applied in many contexts. They show that reviewers and editors ask things such as "how is the history relevant?" and suggest that local knowledge is a distraction from the empirical findings rather than another standpoint from which the findings can be viewed.

Third, in the case of technological catastrophes or engineering failures such as Hurricane Katrina or the 2011 Japan nuclear meltdown, locals may blame science and technology for their pain, maintaining little patience for outsider researchers who seek to bring the methods of science to bear in understanding the event (Button 2010). This blame can impede the willingness 
of local residents to speak with outsider researchers and thus the findings that most fully reflect lived experiences. When the second author of this paper conducted surveys on people's experiences following Hurricane Katrina, he was frequently asked by potential participants to produce evidence of a "local" status (driver's license, business card, home address, cell phone number, or even an e-mail from his local university email account) before the research could commence. Black and white residents alike explained that they were hesitant to speak with outsiders because they were angry over the historical role experts had played in their communities; experts built the faulty levee system, failed to respond properly to the catastrophe, and descended upon New Orleans to conduct in-and-out research not necessarily designed to better their communities. Hoffmann (1999:186) adopted a similar outlook following the Oakland firestorm: "We took on an aura as if we, as a group, were sacred, almost purified by the fire. Outsiders were 'unbaptized' who 'could not understand.' No one who had not suffered the fire could understand."

Fourth, the arrival of outsider expertise into an affected region is often met by locals with skepticism and mistrust, due to the litigious nature of (especially technological) disasters. As Picou, Marshall, and Gill (2004) demonstrate following the Exxon Valdez oil spill, both litigants and defendants mobilized their resources to generate scientific evidence that supported their cases. The long-term effects of such rational-legal-scientific challenges presented to an affected community can erode familial, neighborly, and community relationships that once sustained the place, or create what the authors call a "corrosive community." Although science can certainly help residents make claims that hold up in court, affected communities may end up battling for their share of limited rebuilding and settlement money, which can slow recovery. The ability to purchase and mobilize scientific expertise (Clarke 2006) is often coupled with a pervasive 
distrust of outsiders and their motives. In one salient example, the second-author of this paper attempted in autumn 2012 to make contact with fishermen in Southern Louisiana affected by the 2010 Deepwater Horizon oil spill. Most of the fishermen refused to speak about the spill, citing concerns over how information they share might be used to deny their claims filed against British Petroleum. Although the research process is supposed to be carried out objectively, the results of research are used by multiple parties, and for different political and economic ends. The use and misuse of knowledge by researchers can thus institute a culture in which local people mistrust outside authorities.

\section{INSTITUTIONAL AND FINANCIAL PRIVILEGING OF OUTSIDER RESEARCHERS}

In this section, we establish how institutional and economic barriers can often stymie research by local affected researchers. On the economic front, we look specifically at grant funding. Although grant funding represents only one possible avenue through which particular parties are empowered (or not) to undertake research after a disaster, it nonetheless demonstrates how formal institutions privilege outsider voices. It also helps to explain why we see a lag of disaster work by local affected researchers (which we discuss in the next section).

Given the time and cost associated with social science research, applying for and receiving grant support is increasingly necessary for scholars. Data about funding decisions are instructive regarding who is given access to resources necessary for such investigations. The National Science Foundation's Small Grants for Exploratory Research (SGER) program, for projects associated with Katrina, was disproportionately claimed by researchers living outside of New Orleans and outside of the affected region (Haney and Barber 2013). For instance, only 11 percent of funding went to researchers located in New Orleans, while 73 percent left the Gulf Coast region completely. Within the Social and Economic Sciences, NSF awarded only 9 percent 
of funds to researchers located in New Orleans and 86 percent to researchers outside of the Gulf Coast region. We do not data on the geographic dispersion of applicants for these funds, if such data are available, so our intent is not to suggest that NSF systematically denied funds to local researchers. Rather, it is evident comparatively few local affected researchers received funding that might have facilitated research informed by a more local knowledge about New Orleans and a more personal experience with Hurricane Katrina. Given significant disruptions to local institutions - including libraries, administrative support, and IRB's — as well as personal material affects, accessing funds may simply not have been possible for many local researchers (Haney and Elliott 2013) at the same time that researchers outside the region faced none of these barriers.

TABLE 1. NATIONAL SCIENCE FOUNDATION, SGER FUNDING DISTRIBUTION

\begin{tabular}{|l|l|l|l|l|l|l|}
\hline & $\begin{array}{l}\text { New } \\
\text { Orleans }\end{array}$ & $\begin{array}{l}\text { Non-New } \\
\text { Orleans }\end{array}$ & LA & $\begin{array}{l}\text { Non- } \\
\text { LA }\end{array}$ & $\begin{array}{l}\text { Gulf } \\
\text { Coast } \\
\text { (LA, MS, } \\
\text { AL) }\end{array}$ & $\begin{array}{l}\text { Non-Gulf } \\
\text { Coast }\end{array}$ \\
\hline $\begin{array}{l}\text { All programs } \\
\text { (total \$) }\end{array}$ & 635,237 & $4,908,178$ & $1,225,200$ & $4,318,215$ & $1,489,072$ & $4,054,343$ \\
\hline $\begin{array}{l}\text { All programs } \\
(\%)\end{array}$ & 11.45 & 88.55 & 22.10 & 77.9 & 26.86 & 73.14 \\
\hline $\begin{array}{l}\text { Social and } \\
\text { Economic } \\
\text { Sciences } \\
\text { (total \$) }\end{array}$ & 101,405 & $1,059,898$ & 161,347 & 999,956 & 161,347 & 999,956 \\
\hline $\begin{array}{l}\text { Social and } \\
\text { Economic } \\
\text { Sciences (\%) }\end{array}$ & 8.73 & 91.27 & 13.89 & 86.11 & 13.89 & 86.11 \\
\hline
\end{tabular}

Source: National Science Foundation's (2010) Award Search interface: www. nsf.gov/awardsearch. 
Although disaster research can certainly take place without funding, support provided by NSF and other granting bodies is especially important after a disaster. This money allows researchers to find a place to stay in the affected region while collecting data, for example, while local researchers may be displaced or struggling with rent spikes. This money would also help to provide small incentives to participants in recognition of their time and effort, and to ensure that data entry/transcription and analysis proceeds in a timely fashion. By not earmarking grant money for local researchers, funding agencies such as the NSF are circuitously guaranteeing that work by local affected researchers will be far slower to develop, smaller in scale, and less common than work by outsider researchers. The following section demonstrates the absence of work by such researchers following Hurricane Katrina.

\section{HURRICANE KATRINA RESEARCH BY OUTSIDERS AND INSIDERS}

To look for patterns between research conducted by locals and non-locals, we conducted a March 2014 search of the EBSCOhost database for sociological articles on Hurricane Katrina, which resulted in a total of 449 articles published between September 2005 and December 2013. We organized these articles by research method, including: Qualitative ( $\mathrm{n}=117)$; Quantitative ( $\mathrm{n}=121)$; Content Analysis ( $\mathrm{n}=21)$; Mixed Methods ( $\mathrm{n}=6)$; Essay or Literature Review ( $\mathrm{n}=131)$; Policy Reports ( $\mathrm{n}=33)$; and Methods Papers $(\mathrm{n}=20)$. We focus our analysis here on qualitative research articles because they are the most likely to be epistemologically reflexive, with authors finding space to discuss the impact their social locations, biases, interests, and personal biographies have on the research. They are more likely than quantitative articles to reveal the origins and evolutions of research questions and topics, instead of setting research up as a series of hypotheses. In qualitative work, researchers are also increasingly encouraged by editors to write themselves into their work. 
For each of the articles, we coded authors in terms of their relationship to the affected Gulf Coast region and begin looking for systematic differences in their writings and analyses. Admittedly crude, and with a slight possibility of essentializing (after all, each group brings a diversity of experiences related to disaster), this strategy is a necessary evil if we hope to begin unpacking the differences in how these groups approach their work. Using Google, we searched for each author to extrapolate the institutions with which they were affiliated during 2005 when Hurricane Katrina made landfall, including where they received their degree or where they were faculty affiliated. We coded articles as written by:

- "Insider 1" (authors who were in New Orleans in 2005, including at University of New Orleans, Tulane, etc.);

- "Insider 2" (authors located in the greater Gulf Coast area, including Mississippi, Louisiana, and Alabama, as well as San Antonio and Houston - nearby cities which saw a flood of evacuees from New Orleans);

- "Outsider" (authors who did not fit either category 1 or 2, and who where affiliated with institutions outside of the affected region in 2005);

- "Mixed" authorship (articles written by multiple authors who were Insider $1 \&$ Insider 2, Insider $1 \&$ Outsider, and Insider 2 \& Outsider).

We analyzed those articles written by "Insider 1" and "Outsider" authors; and we excluded those by authors from the larger affected region and those "mixed" articles, as it is impossible to disentangle what work originates from which author. There were a total of 15 qualitative-based sociological articles published on Hurricane Katrina and by authors from the New Orleans region, and 67 published by outsider authors. We used a simple random sampling to select 15 Outsider articles with which to compare the works of Insider 1 authors. We open-coded these articles, focusing on research questions and topics, reflexivity of researchers, researcher relationship to participations, discussions of accessibility to participants, and data.

\section{Patterns in Research by Outsiders}


Qualitative research involving ethnographic observations and in-depth interviewing provides researchers the opportunity to highlight the lived experiences of their participants. The Hurricane Katrina research conducted by Outsiders we sampled here is no exception. These authors brought the experiences of disaster survivors and first responders to the forefront of their research, often helping to project the voices of otherwise marginalized groups. For example, Kemmelmeier, Broadus, and Padilla's (2008:222 and 224) work on tensions between local hurricane "victims" and rescuers reveals the social divisions and violence that characterized interactions post-storm. One interview participant who was stranded in New Orleans witnessed the clash between desperate locals and the police who saw them as looters, “... the cops had caught somebody at a Walgreen's and they were throwing his stuff on the ground, kicking in his face...” Another participant noted: “... there was a pregnant lady with a shopping cart full of baby supplies and they [the NOPD] chased her down... she fell to the ground... and they said they were taking her to jail." And in her work on Honduran migrant kids living (and sometimes working as day laborers) in post-Katrina New Orleans, Ensor (2008) challenges patterns in scientific research that silence the voices of kids. Instead, she provides space for the kids to demonstrate their own resourcefulness, independence, and initiative in recovery.

Despite the focus on participants' voices the researcher is all but missing from these outsider articles. Hesse-Biber and Leckenby (2004) argue that feminist research is accomplished not through a particular method but a particular reflexive approach that considers power in data collection. Yet writing-up quantitative research findings is generally formulaic, with the interpretation of regression coefficients followed by broader conclusions about their meaningfulness. Having emerged from and still largely attached to traditions of objectivity, quantitative scholars generally make themselves invisible in the presentation of their work. The 
qualitative work by outsiders represented here similarly evoke the "god trick" (Haraway 1988), with authors using passive voice, even in their methods sections where they might otherwise unpack the epistemological significant of their research practices and write themselves in. This absence of the researcher may reflect authors' attempts to appear unbiased and unattached from their work, and to convince positivists their work is legitimate. After all, by avoiding writing in the first-person authors make it appear as if some disembodied, unbiased scholar conducted the research; for example, "Participants were recruited in person at Katrina-related meetings and events..." (Peek and Morrissey and Marlatt 2011:1374).

When the authors do use "I" or "We," they pay little attention to how their social locations, standpoints, relationships to participants, and biographies affect the research process and their data. Hawkins and Maurer (2010) are no exception. Although they mention that they "may have overlooked important details" during interviews with participants and worked as posthurricane cleanup volunteers to get close to potential participants, they do not discuss how topical omissions in interviews may have resulted from their outsider status, and thus their lack of local knowledge and experiential knowledge. While evoking "I," the authors' use of firstperson is brief and does not lead to a reflexive discussion of how their statuses as outsiders may have inhibited their ability to bridge experiential gaps with participants, or how their roles as both outsiders and volunteers shaped who they were able to solicit for interviews, the building of rapport with participants, and ultimately their findings.

The Outsider authors' distance from their participants is reflected in their sampling techniques. In Peek et al.’s (2011) work on family adjustment post-storm, they recruited participants through solicitation at Hurricane Katrina related meetings, as well as by posting flyers and scouring aid centers. Their outsider status likely affected their entrée into these 
different sites, who agreed to participate in their study, and the data they garnered from interview; yet, a discussion of how the authors' locations affected these things is absent. The authors also conducted research in Colorado, which may have been convenient for them but is also a site that lay outside of the affected areas and did not see a high rate of relocated evacuees. In Ensor's (2008:284) study of Honduran migrant children, she mentions having spent time interviewing in New Orleans in 2006, with "two short visits in 2007." As Fothergill (2004) notes, this approach and lack of embeddedness in an affected community can limit the epistemic advantages of ethnography as a method and elicit suspicion on behalf of potential participants who might see the outsider researcher as having conflicting interests.

Inductive in nature, the bulk of this research deploys a grounded approach to build theories and concepts. Outsider authors use Hurricane Katrina as a case study to engage broader theoretical debates in different fields and to reveal the larger scholastic lessons of disaster. In Hawkins and Maurer's (2010) work, for example, they suggest social workers need to consider social capital in working with people who experience catastrophic events, and they discuss how "homophilous bonding" or "heterophilous bridging" affects vulnerability and survival. The authors use Hurricane Katrina to apply the notion of social capital in learning more about serving disaster survivors more generally. While certainly important to the field of social work, what gets lost are the contextually specific issues and policies needed to better the lives of the participants, whose experiences are shaped by particular locations, histories, and geographies. Other times, however, there is less of a theoretical contribution to this work; with authors undertaking a descriptive project, such as Johnson and Rainey's (2007) work on some New Orleanians' feelings of injustice in how uneven state recovery aid negatively impacts Historically Black Colleges and Universities. 


\section{Patterns in Research by Insiders}

Reflecting the emphasis of feminist epistemology on reflexivity (Harding 2003; Sprague 2005), Insider 1 authors who published sociological qualitative research on Hurricane Katrina brought themselves into their articles. In fact, all but one of the authors (Lu 2011), invoked "I" or "we" throughout the article, leaving no question that there is an embodied researcher behind the study design, implementation of methods, and presentation of findings. Writing in the firstperson, the authors drew attention to the human experience of doing research, in which they negotiated relationships with people on the ground to collect data and make decisions about the scholarly process.

Writing themselves into their work has different consequences for the data and claims these insiders made. First, we characterize five articles as "navel-gazing," with authors focusing solely on their experiences with disaster and not connecting these experiences to larger structural phenomena. These all come from a special issue on Disaster and Older Adults, where elderly New Orleanians, administrators for retirement homes, and employees of the city's Department of Health and Hospitality weave short memoirs about their experiences with Hurricane Katrina. This journal issue provides space for local voices within scholarly outlets. Illuminating the lived experience of boarding-up homes, helping elderly to navigate FEMA applications, and making decisions about pets' wellbeing highlights tensions between local institutions and government agencies, as well as conflicts around preparedness and evacuation decisions that could evoke future research on disaster. At the same time, these reflections did not translate into methodologically rigorous research or unpack larger, structural patterns such as the effects of age in disaster. 
Second, invoking the "I" at times only served to avoid passive voice, and was not utilized by authors to reflect on how social location informed their research or to make their methods more transparent. In Radcliff’s (2007:27) article on the rebuilding challenges Historically Black Colleges and Universities faced after the hurricane, he discusses the role institutional racism played in African American students experiences of "being taught in a trailer by day and living in a trailer at night." With a 2005 affiliation at Southern University of New Orleans, however, Radcliff does not discuss how his own involvement with an affected university, and thus embeddedness in racialized educational issues, likely prompted his interest in covering student and faculty protest around uneven government recovery efforts. Missing out on the reflexive potential of his localness, he instead uses "I" to situate himself as author rather than as affected scholar, and upholds positivist preferences for the seeming separation of personal experience from research findings.

Third, two articles use personal accounts with disaster in an attempt to carve out a "new genre" of scholarship that complicates the notion of a primary and secondary data source (Batlan 2008; Peña 2006). Using her experiences as a white scholar evacuating with a Black friend, for example, Batlan (2008:171) discusses how race affected both their experience of navigating hotel reservations and perceptions of discrimination on the road, as well as the dangers of being a women returning to a "City of Men":

There were men from the military who paraded through the streets, and drove their Humvees down the narrow lanes of the Garden District; there were an unknown number of contractors... utility workers, Army Corps of Engineers personal, Homeland Security's Immigration and Customs Enforcement officers... disaster aid workers, missionaries, and volunteers. There were a lot of men... Over and over, friends and even 
policemen urged that I "get myself a gun and learn how to use it." New Orleans, they claimed was now a dangerous place for a single woman...

Bordering on auto-ethnography, Batlan (2008:163) moves beyond navel-gazing by emphasizing the theoretical potential of bringing together the lived experience of disaster with scholarly work to "create order out of disorder", and by highlighting the intellectual potential of scholars' personal and highly emotive experiences with disasters such as Hurricane Katrina.

Lastly, there were times when the reflexive efforts of insider researchers, who were affiliated in New Orleans at the time of Hurricane Katrina, did what we argue they can do best: help to design research that both emerges from personal and emotional experiences of trauma and focuses on uncharted (and potentially otherwise unnoticed) territory. For example, Thomas (2009:749) opens his article by discussing how his New Orleans roots allowed him to witness "firsthand how writers, tourism promoters, and visitors to New Orleans have collectively created and perpetuated stories of New Orleans as exotic, dangerous, and unique...” These localized observations inform his article, in which he analyzes promotional materials to explore a "potentially new tourism narrative in the wake of Hurricane Katrina" (Thomas 2009:749) that reinforces the exocticization of Black New Orleanians.

In another example, Mayer et al. (2008:186) come together around their common experiences as Women's Studies faculty in New Orleans to talk about the damage suffered to this department and to women more generally. They take aim at disaster literature, noting, "We have witnessed gender taking a back seat to race and class issues in the description of the crisis...", and discuss how women scholars uniquely situated to bring gender back into this work were "uprooted," and how interdisciplinary programs housing women's studies were vulnerable to institutional "financial exigency" following the storm. A gender studies "brain drain" occurred 
post-Katrina, with University of New Orleans losing "nearly one-third of the interdisciplinary women studies faculty" (Mayer et al. 2008:187). As local affected scholars on the ground and located in local gender studies programs, the authors explore questions about gender, epistemology, and the future of women's studies in New Orleans. Their experiences around struggles to return to the city and to pick-up their work informed the questions they asked and what they found, forging a unique line of inquiry around the effects of Hurricane Katrina.

Luft's (2008) article on the racialization and gendering of violence in post-Katrina New Orleans too reveals the connection between experience with disaster and the formation of research questions. Her questions around white women's experiences with sexual assault and the criminalization of the "anonymous" Black male community in New Orleans emerged via stories she and colleagues heard from local women they worked with as part of the Common Ground Collective (CCC). She also centers herself as an "older, local, white, anti-racist, feminist" (Luft 2008:9) with ties to an anti-racist organization, making it clear how this standpoint informs her interest in issues of intersectional inequality, as well as her access to members of local civil rights groups that might otherwise be difficult for scholars to infiltrate. Being an insider, Luft had relationships with women who had experienced sexual assault, rather than coming in as an outsider and attempting to solicit interviews with this vulnerable and possibly guarded population. This reflects how her insider status allowed access to and trust from participantsnot to mention her immersion in the lives of these women as a CCC volunteer.

While her reflexive account does fall a bit short, with no details on how exactly her location informed the data she gathered, in a later article Luft (2009:500-501) clearly emplaces her work in her local identity, role within her community, and roots in the city: 
As a sociologist at the University of New Orleans with research interests in race, gender, and social movements, and a white woman activist in local struggles for racial and gender justice, I build my discussion out of participant observation in post-Katrina New Orleans-based movements for a just reconstruction.

In her more recent work, Luft (2012) adds that “... while still in evacuation myself, I was invited to join a national conference call with organizers who were forming PHRF [People's Hurricane Relief Fund]. When I returned to New Orleans in January 2006, I began participant-observation in PHRF and several other grassroots reconstruction efforts" (Luft 2012:234). Luft (2008; 2009; 2012) exposes a line of scholarly inquiry that is consistently reflexive and emerges from her emotional and personal experiences with having lived in and worked for movement organizations in New Orleans before and after Hurricane Katrina. Her insightful analyses of the dynamics of post-Katrina social justice organizations emerge precisely from her participation in those movements, her experience of the disaster, and her ability to dedicate herself fully to understanding their evolution over a long period of time - insights all gained or enhanced by virtue of having a shared experience with the local community and by living within the recovering city.

\section{Comparing Insider and Outsider Research}

Overall, an analysis of Outsider qualitative research on Hurricane Katrina reveals several important patterns. First and foremost, based in ethnographic observations and/or in-depth interviewing techniques, they rely on participants' lived experiences as data and tackle pressing issues related to disaster. Yet, they more often than Insider authors evoke passive voice and avoid reflexive analyses of how their standpoints and social locations shaped their research. In this way, outsiders demonstrate techniques that veil their biases, interests, and how their outsider 
location may have created barriers to community immersion and access to participants' emotional experiences (Erikson 1976; Fothergill 2004). They consequently frame their work in ways more compatible with or lauded by positivists and quantitative scholars, who often remove themselves from the presentation of their work and thus project a sort of disembodied and unattached researcher (Haraway 1988). Outsiders also used Hurricane Katrina as a case study to understand the generalizability of and to grow theories related to issues such as social work. Insiders, on the other hand, tackled localized problems following the storm (i.e., activities of local organizations, local laws and regulations) - problems rooted in New Orleans' unique geography and politicized history.

However, even some work by locals (or former-locals) suffers from a lack of in-depth reflection that connects their experiences with Hurricane Katrina to their research. While they were still creating local, experiential based research (for example HBUCs), it is harder to demonstrate this. Others privilege "navel-gazing," sharing potentially epistemic important information but lacking the empirical richness of more systematic research (Hidalgo and Barber 2007) for a collection of essays bringing together personal experiences of Hurricane Katrina with scholarly analyses). For the bulk of this insider work, however, the benefits of locally and experientially informed research is clear: it creates new lines of inquiry, helps to overcome barriers to participant access and immersion limitations, focuses on historically-informed local issues, and ultimately yields scholarly questions and data that might otherwise escape the attention of outsider researchers (Mayer et al. 2008 on the local women's studies brain drain post-storm, for example).

It is also noteworthy that the articles by outsiders tended to utilize larger sample sizes and, importantly, to appear in journals with a higher impact factor than insiders. Little disaster 
scholarship tends to appear in mainstream sociology journals, but the work by insiders are generally further from the mainstream than the outsider articles. Although measuring these differences is beyond the scope of this analysis, outsider work appeared in outlets such as Disasters, Journal of Family Issues, and Children, Youth and Environments, while insider research appeared largely in NWSA Journal — a well-known women's studies journal — as well as in less known outlets such as Families in Society and The Oral History Review. The differences in sample sizes and in publication prestige may reflect the comparative ease at which outsiders were able to get grant funding and to move more quickly post-disaster. And because this work appears in journals with higher impact factors, it will likely be downloaded and read more often, and therefore has the potential to more greatly influence the field. It also means that outsiders are able to leverage more career traction through tenure and promotion decisions, which often take impact into account.

\section{CONCLUSION}

In this paper, we make the case for a situated knowledge of disasters, catastrophes, and crises. Applying a feminist standpoint framework, we explore the epistemological possibilities of disaster research by local affected scholars who are themselves caught-up in the aftermath of disaster. We demonstrate how an experiential gap between outsider researchers and local participants create barriers to knowing, and how these barriers may be bridged by scholars who have both personal experience and scholarly insight (Smith 1987).

Connecting knowing and knowledge (Smith 1987) involves rethinking what constitutes valid data and dismantling the ethic of objectivity concerned with separating "the knower from what [s/]he knows" (Smith 2004:88)—which colonizes the voices of some while reserving scientific authority for others (Collins 1986; 1990; Haraway 1988; Harding 1986; Longino 1989; 
Nagel 1986). Those who have not experienced a disaster firsthand create important knowledge about events and have informed vital preparedness and recovery practices. Positivist scientific traditions of projecting an unattached and disembodied observer (Haraway 1988; Nagel 1986), however, continue to privilege outsider researchers, and this is true in the sociological disaster literature. We show how affected researchers are marginalized through academic processes that ignore the epistemological barriers of outsiders, do not earmark funding for local scholars, and discourage experiential-based scholarship. While feminist epistemology has indeed made inroads into sociological subfields such as gender studies and critical race theory, disaster research has been slow to take-up this approach.

There are of course epistemic risks associated with deploying experiential analyses in research. For example, by using "affected persons" as an umbrella for all persons who experience loss or dislocation due to disaster, researchers may create a false generic, ignoring the diversity of experiences present in an affected region. After all, there is no monolithic "New Orleans Community," but rather diverse groups of people and neighborhoods divided by race and class; and so "localness" may not always trump differences between researcher and participant. Further, local researchers who deploy convenience sampling may end up speaking largely to those with whom they are closest, capturing the experiences of some individuals while ignoring the voices of others. Social networks are generally homophilous, meaning that individuals often spend time with those who are most like themselves — not only in terms of gender, race/ethnicity, or social class, but also in terms of political views, residential location, and tastes/affinities.

We do not advocate for the replacement of conventional outsider disaster research with a more locally driven approach. Rather, we argue for the systematic inclusion of experiential-based research that will help to generate a more diverse and inclusive disaster literature-a diversity of 
discourses (Sprague 2005) — reveal unique lines of inquiry, encourage a reflexive discussion of fields of power, and ultimately create new paths to knowledge. Structural and disciplinary changes whereby grant funding is earmarked for local researchers, editors and reviewers recognize the important contributions of locals, and outsider researchers seek collaborators from the affected region are a start. The United Nations and World Bank (2010) projects that the number of urbanites at risk of a "natural" disaster will double by 2050 and yearly global losses from disasters will triple by 2100 ; so disasters are sure to increasingly capture the attention of the social science community. Tierney (2007:520) suggests that if scholars hope to move disaster sociology "from the margins to the mainstream," we must "integrate the study of disasters with core sociological concerns." A feminist epistemological approach to disaster is one way to do this since it tackles concerns about social injustice and inequality in both the experience of disaster and the creation of disaster research.

\section{REFERENCES}

Adams, Vincanne. 2013. Markets of Sorrow, Labors of Faith: New Orleans in the Wake of Katrina. Durham, NC: Duke University Press.

Batlan, Felice. 2008. "Weathering the Storm Together (Torn Apart by Race, Gender, and Class).” NWSA Journal 20:163-184.

Beck, Ulrich. 2009. World at Risk. Malden, MA: Polity Press.

Bordo, Susan. 1987. The Flight of Objectivity: Essays on Cartesianism Culture. Albany, NY: SUNY Press.

Brun, Georg, Ulvi Doguoglu, and Dominique Kuenzle. 2008. Epistemology and Emotions. Surrey: Ashgate. 
Button, Gregory. 2010. Disaster Culture: Knowledge and Uncertainty in the Wake of Human and Environmental Catastrophe. Walnut Creek, CA: Left Coast Press.

Campanella, Richard. 2007. “An Ethnic Geography of New Orleans.” The Journal of American History 94:704-715.

Clarke, Lee. 2006. Worst Cases: Terror and Catastrophe in the Popular Imagination. Chicago, IL: University of Chicago Press.

Collins, Patricia Hill. 1997. “Comment's on Hekman's 'Truth and Method: Feminist Standpoint Revisited': Where's the power?" Signs: Journal of Women in Culture and Society 22:375381.

Collins, Patricia Hill. 1990. Black Feminist Thought: Knowledge, Consciousness, and the Politics of Empowerment. New York, NY: Routledge.

Collins, Patricia Hill. 1986. "Learning from the Outsider Within: The Sociological Significance of Black Feminist Thought.” Social Problems 33:S14-S32.

David, Emmanuel. and Elaine Enarson. 2012. The Women of Katrina: How Gender, Race, and Class Matter in an American Disaster. Nashville, TN: Vanderbilt University Press.

Enarson, Elaine. 2012. "Women and Girls Last? Averting the Second Post-Katrina Disaster. Pp. 10-14 in The Women of Katrina: How Gender, Race, and Class Matter in an American Disaster, edited by Emmanuel David and Elaine Enarson. Nashville, TN: Vanderbilt University Press.

Ensor, Marisa O. 2008. "Displaced Once Again: Honduran Migrant Children in the Path of Katrina. "Children, Youth and Environments 18:280-302.

Erikson, Kai T. 1976. Everything in Its Path: Destruction of Community in the Buffalo Creek Flood. New York, NY: Simon and Schuster. 
Fee, Elizabeth. 1981. "Women's Nature and Scientific Objectivity.” Women's Nature:

Rationalizations of Inequality, ed. Marion Lowe and Ruth Hubbard New York, NY: Pergamon Press.

Fleischman, Alan R., Lauren Collogan, and Farris Tuma. 2006. "Ethics in Disaster Research." Pp. 78-91 in Methods for Disaster Mental Health Research, edited by F. H. Norris, S. Galea, M. J. Friedman, and P. J. Watson. New York, NY: Guilford Press.

Fortun, Kim. 2001. Advocacy After Bhopal: Environmentalism, Disaster, New Global Orders. Chicago, IL: University of Chicago Press.

Fothergill, Alice. 2004. Heads above Water: Gender, Class, and Family in the Grand Forks Flood. Albany, NY: State University of New York Press.

Gorton, Kristyn. 2007. "Theorizing Emotion and Affect: Feminist Engagements.” Feminist Theory 8:333-348.

Haney, Timothy J., and Kristen Barber. 2013. "Reconciling Academic Objectivity and Subjective Trauma: The Double Consciousness of Sociologists Who Experienced Hurricane Katrina.” Critical Sociology 39:105-122.

Haney, Timothy, and James R. Elliott. 2013. "The Sociological Determination: A Reflexive Look at Conducting Local Disaster Research After Hurricane Katrina.” Sociology Mind $3: 7-15$.

Haraway, Donna. 1988. "Situated Knowledges: The Science Question in Feminism and the Privilege of Partial Perspective.” Feminist Studies 14:575-599.

Harding, Sandra G. 2003. The Feminist Standpoint Theory Reader: Intellectual and Political Controversies. New York, NY: Routledge. 
Harding, Sandra G. 1986. The Science Question in Feminism. Cornell, NY: Cornell University Press.

Hawkins, Robert L., and Katherine Maurer. 2010. "Bonding, Bridging and Linking: How Social Capital operated in New Orleans Following Hurricane Katrina.” British Journal of Social Work 40:1777-1793.

Hawkins, Robert L., and Katherine Maurer. 2011. "You Fixed My Community, You have Fixed My Life: The Disruption and Rebuilding of Ontological Security in New Orleans.” Disasters 35:143-159.

Henderson, Tammy L., Maria Sirois, Angela Chia-Chen Chen, Christopher Airriess, David A. Swanson, and David Banks. 2008. “After a Disaster: Lessons in Survey Methodology from Hurricane Katrina.” Population Research and Policy Review 28:67-92.

Hesse-Biber, Sharlene Nagy, Eds. 2012. Handbook of Feminist Research: Theory and Praxis, 2nd Edition. Thousand Oaks, CA: Sage Publications.

Hesse-Biber, Sharlene Nagy. and Denise Leckenby. 2004. "How Feminists Practice Social Research.” Pp. 209-226 in Feminist Perspectives on Social Research, edited by Sharlene Nagy Hesse-Biber and Michelle L. Yaiser. New York, NY: Oxford University Press.

Hidalgo, Danielle A. and Kristen Barber, Eds. 2007. Narrating the Storm: Sociological Stories of Hurricane Katrina. Newcastle, U.K.: Cambridge Scholars Press.

Hoffman, Susanna M. 1999. "The Regenesis of Traditional Gender Patterns in the Wake of Disaster.” Pp. 174-191 in The Angry Earth: Disaster in Anthropological Perspective, edited by A. Oliver Smith and S. M. Hoffman. New York, NY: Routledge.

Jagger, Alison M. 1989. “Love and Knowledge: Emotion in Feminist Epistemology.” Inquiry: An Interdisciplinary Journal of Philosophy 32:151-176. 
Johnson, Glenn S., and Shirley A. Rainey. 2007. "Hurricane Katrina Impact on Three Historically Black Colleges and Universities 9HBCUs): Voices from Displaced Students." Race, Gender \& Class 14:100-119.

Jones, Russell T., James M. Hadder, Franklin Carvajal, Sara Chapman, and Apryl Alexander. 2006. "Conducting Research in Diverse, Minority, and Marginalized Communities.” Pp. 265-277 in Methods for Disaster Mental Health Research, edited by F. H. Norris, S. Galea, M. J. Friedman, and P. J. Watson. New York, NY: Guilford Press.

Kemmelmeir, Markus, Angela D. Broadus, and Joshua B. Padilla. 2008. "Inter-group Aggression in New Orleans in the Immediate Aftermath of Hurricane Katrina." Analyses of Social Issues and Public Policy 8:211-245.

Longino, Helen E. 1990. Science as Social Knowledge: Values and Objectivity in Scientific Inquiry. Princeton, NJ: Princeton University Press.

Longino, Helen E. 1989. "Feminist Critiques of Rationality: Critiques of Science or Philosophy of Science?” Women's Studies International Forum 12:261-269.

Lu, Alexander. 2011. "Stress and Physical Health Deterioration in the Aftermath of Hurricanes Katrina and Rita.“ Sociological Perspectives 54:229-250.

Luft, Rachel E. 2012. “Community Organizing In the Katrina Diaspora: Race, Gender, and the Case of the People's Hurricane Relief Fund.” Pp. 233-255 in Displaced: Life in the Katrina Diaspora, edited by Lynn Weber and Lori Peek. Austin, TX: University of Texas Press.

Luft, Rachel E. 2009. “Beyond Disaster Exceptionalism: Social Movement Developments in New Orleans After Hurricane Katrina.” American Quarterly 61:499-527. 
Luft, Rachel E. 2008. “Looking for Common Ground: Relief Work in Post-Katrina New Orleans as an American Parabel of Race and Gender Violence. NWSA Journal 20:5-31.

Marks, Ronald E. 2008. “Canoeing Home: A Personal and Professional Journey Through Murky Waters." Traumatology 14:14-20.

Mayer, Vicki, Beth Willinger, Pamela Jenkins, Susan Tucker, Susanne Dietzel, Pamela Waldron Moore, Betsy Hones Hemenway, Crystal Kile, Violet Harrington Bryan, and Julia Reinemen. 2008. “Losing Ground but Finding the High Road: Teaching Women’s Studies in Post-Katrina New Orleans.” NWSA Journal 20:185-192.

Nagel, Thomas. 1986. The View from Nowhere. New York, NY: Oxford University Press.

Oliver-Smith, Anthony, and Susanna M. Hoffman, Eds. 1999. The Angry Earth: Disaster in Anthropological Perspective. New York, NY: Routledge.

Pardee, Jessica. 2014. Surviving Katrina: Low-Income Women's Experiences from Evacuation to Recovery. Boulder, CO: Lynne Rienner Publishers.

Parsons, Talcott. [1937] 1968. The Structure of Social Action. New York, NY: The Free Press. Peek, Lori, Bridget Morrissey, and Holly Marlatt. 2011. "Disaster Hits Home: A Model of Displaced Family Adjustment After Hurricane Katrina.” Journal of Family Issues $3: 1371-1396$.

Peña, Allison H. 2006. "Wade in the Water: Personal Reflections on a Storm, a People, and a National Park." American Anthropologist 108:781-798.

Picou, J. Steven, Brent K. Marshall, and Duane A. Gill. 2004. "Disaster, Litigation, and the Corrosive Community." Social Forces 82:1493-1522.

Quarantelli, Enrico L. 2005. “A Social Science Research Agenda for the Disasters of the $21^{\text {st }}$ Century: Theoretical, Methodological, and Empirical Issues and their Professional 
Implementation." Pp. 325-396 in What is a Disaster? New Answers to Old Questions, edited by RW Perry and EL Quarantelli. Philadelphia: XLibris Corp.

Radcliff, Michael. 2007. "SUNO Family Vows to Fight the Systematic Destruction of the School and Its Legacy." Race, Gender \& Class 14:96-99.

Smith, Dorothy E. 2004. “Women's Perspectives as a Radical Critique of Sociology.” Pp. 84-96 in Feminism and Methodology: Social Science Issues, edited by S. Harding. Bloomington: Indiana University Press.

Smith, Dorothy. 1990. The Conceptual Practices of Power. Boston, MA: Northeastern University Press.

Smith, Dorothy E. 1987. The Everyday World as Problematic: A Feminist Sociology. Boston: Northeastern University Press.

Sprague, Joey. 2005. Feminist Methodologies for Critical Researchers. Lanham, MD: Rowman and Littlefield.

Thomas, Lynell L. 2009. “'Roots Run Deep Here': The Construction of Black New Orleans in Post-Katrina Tourism Narratives.” American Quarterly 61:749-768.

Tierney, Kathleen. 2007. "From the Margins to the Mainstream? Disaster Research at the Crossroads." Annual Review of Sociology 33:503-525.

United Nations and World Bank. 2010. Natural Hazards, UNnatural Disasters. Report by the Global Facility for Disaster Reduction and Recovery. Available at: http://www.gfdrr.org/gfdrr/NHUD-home 